\title{
E2FBP1 antagonizes the $\mathrm{p} 16^{\mathrm{INK} 4 \mathrm{~A}}-\mathrm{Rb}$ tumor suppressor machinery for growth suppression and cellular senescence by regulating promyelocytic leukemia protein stability
}

\author{
Yayoi Fukuyo ${ }^{1,4}$, Akiko Takahashi ${ }^{2}$, Eiji Hara ${ }^{2}$, Nobuo Horikoshi ${ }^{3}$, Tej K. Pandita ${ }^{3}$, Takuma Nakajima ${ }^{4}$ * \\ ${ }^{I}$ Department of Immunology, Tulane National Primate Research Center, Covington LA 70433, USA; ${ }^{2}$ Division of \\ Cancer Biology, The Cancer Institute, Japanese Foundation for Cancer Research, Tokyo 135-8550, Japan; ${ }^{3}$ Division \\ of Molecular Radiation Biology, Department of Radiation Oncology, University of Texas Southwestern Medical Center, \\ Dallas TX 75390-8807, USA; ${ }^{4}$ Section of Bacterial Pathogenesis, Graduate School, Tokyo Medical and Dental \\ University, Tokyo 113-8549, Japan
}

Cellular senescence is an irreversible cell cycle arrest triggered by the activation of oncogenes or mitogenic signaling as well as the enforced expression of tumor suppressors such as $\mathrm{p53}, \mathrm{p}^{\mathrm{INK4A}}$ and promyelocytic leukemia protein (PML) in normal cells. E2F-binding protein 1 (E2FBP1), a transcription regulator for E2F, induces PML reduction and suppresses the formation of PML-nuclear bodies, whereas the down-regulation of E2FBP1 provokes the PML-dependent premature senescence in human normal fibroblasts. Here we report that the depletion of E2FBP1 induces the accumulation of PML through the Ras-dependent activation of MAP kinase signaling. The cellular levels of $\mathrm{p}^{16^{\mathrm{INK} 4 \mathrm{~A}}}$ and $\mathrm{p53}$ are elevated during premature senescence induced by depletion of E2FBP1, and the depletion of p16 ${ }^{\mathrm{INK} 4 \mathrm{~A}}$, but not p53 rescued senescent cells from growth arrest. Therefore, the premature senescence induced by E2FBP1 depletion is achieved through the p16 ${ }^{\mathrm{INK} 4 \mathrm{~A}}-\mathrm{Rb}$ pathway. Similar to human normal fibroblasts, the growth inhibition induced by E2FBP1 depletion is also observed in human tumor cells with intact $\mathrm{p} 16^{\mathrm{INK4A}}$ and $\mathrm{Rb}$. These results suggest that E2FBP1 functions as a critical antagonist to the $\mathrm{p} 16^{\mathrm{INK} 4 \mathrm{~A}}-\mathrm{Rb}$ tumor suppressor machinery by regulating PML stability.

Keywords: E2F-binding protein 1; senescence; cell cycle; ubiquitin; promyelocytic leukemia protein

International Journal of Oral Science (2011) 3: 200-208. doi: 10.4248/IJOS 11071

Introduction

In most human tumors, abnormality in $\mathrm{p} 16^{\mathrm{INK} 4 \mathrm{~A}}-\mathrm{Rb}$ and/or p14 ${ }^{\mathrm{ARF}}$-p53 pathways disturbs cell cycle control. Remarkably, many tumors are $\mathrm{p} 16^{\mathrm{INK} 4 \mathrm{~A}}$-deficient and

*Correspondence: Takuma Nakajima

Tel: 81358035 456; Fax: 81459827141

E-mail: takman.bac@tmd.ac.jp

Received 22 April 2011; Accepted 24 August 2011 have cyclin D overexpression [1]. p16 $6^{\mathrm{INK} 4 \mathrm{~A}}$ inhibits the catalytic activity of cyclin D-CDK4/6 complex, and increases hypophosphorylated $\mathrm{Rb}$ protein, which result in G1 phase cell cycle arrest by inactive $\mathrm{Rb}-\mathrm{E} 2 \mathrm{~F}$ complex [2-3]. Thus, p16 ${ }^{\mathrm{INK} 4 \mathrm{~A}}$ functions as an important tumor suppressor as it controls cell cycle progression. The expression level of $\mathrm{p} 16^{\mathrm{INK} 4 \mathrm{~A}}$ is low in primary human fibroblasts and high in senescent fibroblasts [4-5]. siRNA-mediated $\mathrm{p} 16^{\mathrm{INK} 4 \mathrm{~A}}$ knockdown rescues senescent cells from growth arrest [6-7], arguing a critical role 
of $\mathrm{p} 16^{\mathrm{INK} 4 \mathrm{~A}}$ in replicative senescence. In senescent cells, p53 is also accumulated and activated by acetylation and phosphorylation [8-9]. In response to oncogenic stimuli, such as ectopic activation of Ras-MAPK pathway, primary fibroblasts exit to premature senescence associated with elevation of $\mathrm{p} 16^{\mathrm{INK} 4 \mathrm{~A}}$ and $\mathrm{p} 53$ levels [10-15].

E2FBP1/DRIL1/hARID3A is a member of A/T-rich interaction domain (ARID) family protein [16] and an E2F1 associated factor that increases E2F/DP-dependent transcription [17], a human orthologue of mouse B-cell regulator of $\operatorname{IgH}$ transcription (Bright) and drosophila dead ringer (Dri) [18-19] expressed ubiquitously in various tissues. More recently, we reported that E2FBP1 acts as a transcriptional suppressor against viral immediate early gene transcription in an intrinsic cellular defense uniquely observed in passage-limited human diploid fibroblast (HDF) cells infected with herpes simplex virus type 1 infection [20]. E2FBP1 also functions as a negative regulator of promyelocytic leukemia proteinnuclear bodies (PML-NBs) [21], which are recognized as gatekeepers of cellular integrity. PML-NBs respond to various cellular events, including the induction of oncogenic transformation and virus infections. The increase in size and numbers of PML-NBs deprive proliferative potential and force cells into premature senescence [2223] or apoptosis [24]. During the oncogenic Ras-induced premature senescence, PML is up-regulated through the activation of MAPK cascade and contributes ultimately to the cell cycle arrest and senescence mediated by $\mathrm{p} 16^{\mathrm{INK} 4 \mathrm{a}} / \mathrm{Rb}$ - and/or p53-pathways [13-15]. E2FBP1 interacts with the components of PML-NBs such as PML, speckled protein (Sp100), and p53, as well as E2F2/4 in vivo and in vitro. Moreover, siRNA-mediated E2FBP1 knockdown results in increases of PML-NBs in size and number, and subsequently induces PML-dependent premature senescence of HDF cells along with the up-regulation of $\mathrm{p} 16^{\mathrm{INK} 4 \mathrm{~A}}$ and $\mathrm{p} 53$ [21]. In agreement with this, the ectopic expression of E2FBP1 rescues oncogenic Ras-induced premature senescence [25], and thus E2FBP1 plays an essential role for maintenance of proliferative potential of human cells. However, the mechanism by which E2FBP1 dissociates PML-NBs remains elusive.

Here we report that the molecular mechanism of E2FBP1-induced PML-NBs dissociation is through ubiquitin-dependent degradation of PML. Down-regulation of E2FBP1, induced by oncogenic Ras expression, induces premature senescence and requires an intact $\mathrm{p} 16^{\mathrm{INK} 4 \mathrm{~A}}$ pathway. Therefore, our study reveals that E2FBP1 antagonizes PML-dependent $\mathrm{p} 16^{\mathrm{INK} 4 \mathrm{~A}} / \mathrm{Rb}$-mediated growth suppression and senescence.

\section{Materials and method}

\section{Plasmids and synthetic oligonucleotides}

HA-E2FBP1 and HA-PML-IV were subcloned into pcDNA3 to construct expression plasmids. Human $\mathrm{H}-{ }^{\mathrm{V} a s}{ }^{\mathrm{V} 12}$ was cloned in pLenti6 for preparation of recombinant lentiviruses. Coding units for shRNAs in double strands were synthesized and linked to U6 promoter in pLenti6 plasmid according to the manufacturer's instructions (Invitrogen, Carlsbad, USA). Sequences for anti-E2FBP1 shRNA are following; A1: CACCGATGTAACGTGCGCTTCAAGTGTGCTGTCCTTGGAGTG CACGTTGCATC; A2: CACCGAGATTAACGGTATCGTGTGTGTGCTGTCCACATGATGCCGTTGATCTC; A3: CACCCTGTGGACCCGATACGTGAACGTGTGCTGTCCGTTCATGTATTGGGTCCGCAG Anti-p16 ${ }^{\text {INK4A }}$ shRNA was prepared as stated by the researchers [26], and the sequence of control shRNA was previously described [27]. shRNA expression plasmid, piGENEE2FBP1 was generated by inserting anti-E2FBP1 shRNA sequence; CAAGCAGTTCTACGGACTCGATGGGGACCCCCTTCCTGTCAGGGGTCCCCGTCGAGTTCGT AGAGCTGCTTGGTAC to piGENEtRNA vector (iGENE Therapeutics, Tokyo, Japan) between Sac I and Kpn I sites.

\section{Cell culture, transfection and infection}

TIG-3 human fetal lung derived passage-limited diploid fibroblast cells between populator doubling (PD) number 36 and 50, human cancer cell lines such as KB, A431, Saos2, MCF7, and 293FT human embryonic kidney cell line (Invitrogen, Carlsbad, USA) were cultivated in Dulbecco's modified Eagles medium (DME) supplemented with $8 \%$ fetal calf serum (FCS). HCT116 was cultivated in McCoy's 5A medium supplemented with $10 \%$ FCS. For transfection with plasmid DNA, cells were plated to be $50 \%$ confluent, and transformed with FuGene 6 transfection reagent (Roche Applied Science, Indianapolis, USA). For recombinant lentivirus infection, TIG-3 cells plated between $1 \times 10^{6}-2 \times 10^{6}$ cells in a $10 \mathrm{~cm}$ dish were incubated with $10 \mathrm{~mL}$ of freshly prepared virus stock supernatant that contains $0.5 \times 10^{6}-5 \times 10^{6}$ viruses $\cdot \mathrm{mL}^{-1}$ for $12 \mathrm{~h}$ in the presence of $6 \mu \mathrm{g} \cdot \mathrm{mL}^{-1}$ polybrene. The cells were then overlaid with $10 \mathrm{~mL}$ of fresh medium containing $4 \mu \mathrm{g} \cdot \mathrm{mL}^{-1}$ Brasticidin-S- $\mathrm{HCl}$ for $30 \mathrm{~h}$ and cultivated for $2 \mathrm{~d}$ with fresh medium without the Brasticidin. The cells were subsequently replated at $40 \%-$ $50 \%$ confluence and grown until they were analyzed. For growth assay using lentiviruses, TIG-3 cells at 47 PD were infected with lentiviruses carrying expression unit of indicated shRNAs at total multiplicity of infection $(\mathrm{MOI})=2\left(\right.$ e.g. MOI=1 of anti-p16 ${ }^{\mathrm{INK} 4 \mathrm{~A}}$ shRNA-expression 
virus plus $\mathrm{MOI}=1$ of $\mathrm{A} 2$-expression virus: the sum of the virus mixture contains $\mathrm{MOI}=2$ ). Infected cells were selected with antibiotics, and counted at the indicated cultivation periods.

\section{Lysate preparation and Western blotting}

Cells were washed twice with PBS, lysed in the lysis buffer $\left(400 \mathrm{mmol} \cdot \mathrm{L}^{-1} \mathrm{NaCl}, 50 \mathrm{mmol} \cdot \mathrm{L}^{-1} \mathrm{HEPES}-\mathrm{Na}\right.$, $\mathrm{pH} 7.0,1 \mathrm{mmol} \cdot \mathrm{L}^{-1}$ ethylene diamine tetraacetic acid (EDTA), and $0.1 \%$ NP-40), and clarified by centrifugation. Protein concentration was determined using the BCA protein assay kit (Sigma-Aldrich, St. Louis, USA). The protein sample $(30 \mu \mathrm{g})$ was separated on SDS-PAGE gels, and transferred to immobion-P membranes (Millipore, Billerica, USA). To detect the antigen, blots were blocked in TBS-T $\left(25 \mathrm{mmol} \cdot \mathrm{L}^{-1}\right.$ tris- $\mathrm{HCl}, \mathrm{pH} 8.0$, $137 \mathrm{mmol} \cdot \mathrm{L}^{-1} \mathrm{NaCl}$, and $2.7 \mathrm{mmol} \cdot \mathrm{L}^{-1} \mathrm{KCl}$, and $0.1 \%$ Tween 20) containing 5\% skim milk (Difco, Detroit, USA) for $30 \mathrm{~min}$, and incubated with primary antibody for $2 \mathrm{~h}$. The blots were incubated with secondary antibody conjugated with horseradish peroxidase for $1 \mathrm{~h}$. Protein bands were visualized by Lumi-Light ${ }^{\text {PLUS }}$ western blotting substrate (Roche Applied Science, Indianapolis, USA). Immunoassays were performed with anti-E2FBP1 polyclonal antibody (BL665, Bethyl Laboratories, Montgomery, USA), Anti-p $16^{\mathrm{INK} 4 \mathrm{~A}}$ polyclonal (C-20), anti-p2 ${ }^{\mathrm{CIP} 1}$ polyclonal, anti-p53 monoclonal (DO-1), anti-PML monoclonal (PG-M3), anti-Cyclin E polyclonal (M-20) and anti-Daxx polyclonal (C-20) antibodies were obtained from Santa Cruz Bio-technology (Santa Cruz, USA). Anti-Sp100 polyclonal was obtained from ChemiconMillipore (Watford, UK). Anti-Ras monoclonal (\#18), anti-Rb monoclonal (G3-245), anti-ERK1 monoclonal (MK12), anti-phospho-ERK1/2 (pT202/pY204) monoclonal (\#20A), anti-p38/SAPK2a monoclonal (\#27), and anti-phospho-p38SAPK (pT180/pY 182) monoclonal (\#30) antibodies were obtained from BD Biosciences (San Jose, USA). Anti-tubulin monoclonal (DM-1A) was obtained from ICN Biomedicals (Irvine, USA).

\section{Detection of PML ubiquitylation}

For ubiquitination assays, $2 \mathrm{~d}$ after transfection, cells were treated with $10 \mu \mathrm{mol} \cdot \mathrm{L}^{-1}$ proteasome inhibitor MG115 for $8 \mathrm{~h}$ and harvested by boiling for $5 \mathrm{~min}$ in lysis buffer ( $1 \%$ sodium dodecyl sulfate $(\mathrm{SDS}), 1 \mathrm{mmol} \cdot \mathrm{L}^{-1}$ EDTA in plosphate buffer saline (PBS) for protein analyses.

\section{siRNA-mediated down-regulation}

The target sequences for siRNA-Control and E2FBP1 have been described previously [21]. siRNAs were synthesized by Japan Bioservice Co. (Saitama, Japan). Trans- fection into TIG-3 cells was performed with oligofectamine (Life Technologies, Carlsbad, USA).

\section{$S A-\beta$-gal assay}

SA- $\beta$-gal assay was performed as described [28]. Briefly, cells were fixed with 3\% formaldehyde for 5 min, washed with PBS, and incubated at $37{ }^{\circ} \mathrm{C}$ with staining buffer $\left(1 \mathrm{mg} \cdot \mathrm{L}^{-1}\right.$ 5-bromo-4-chloro-3-indolyl- $\beta$ D-galactopiranoside, $5 \mathrm{mmol} \cdot \mathrm{L}^{-1}$ potassium ferrocyanide, $5 \mathrm{mmol} \cdot \mathrm{L}^{-1}$ potassium ferricyanide, $150 \mathrm{mmol} \cdot \mathrm{L}^{-1} \mathrm{NaCl}$, $2 \mathrm{mmol} \cdot \mathrm{L}^{-1} \mathrm{MgCl}_{2}, 40 \mathrm{mmol} \cdot \mathrm{L}^{-1}$ citric acid/sodium phosphate, and $\mathrm{pH} 6.0$ ) for $12 \mathrm{~h}$.

\section{Colony formation assay}

Cancer cell lines were plated at $1 \times 10^{6}$ per $35-\mathrm{mm}$ dish in triplicate and transfected with piGENE vector or piGENE-E2FBP1. Cells were replanted in 100-mm dishes the next day, cultivated in the presence of $5 \mu \mathrm{g} \cdot \mathrm{mL}^{-1}$ of puromycin for $48 \mathrm{~h}$, and subsequently developed colonies for two weeks in the presence of $1 \mu \mathrm{g} \cdot \mathrm{mL}^{-1}$ of puromycin. The puromycin-resistant colonies were stained with $0.1 \%$ crystal violet and then calculated using ImageJ software.

\section{Results}

E2FBP1 induces degradation of PML through polyubiquitylation

To determine whether E2FBP1-dependent dissociation of PML-NBs is a consequence of degradation of PML, 293FT cells were transfected with expression plasmids for HA-E2FBP1, HA-tagged 633-residue isoform IV of PML (HA-PML-IV) which is a major component of PMLNBs, and humanized green fluorescent protein (hrGFP). To eliminate the influence of squelching of transcription factors, the amount of plasmids were adjusted with the empty vector pcDNA3 that contains a cytomegalovirus (CMV) early gene promoter for common to all expression plasmids. Ectopic expression of E2FBP1 reduced the amount of PML-IV in dose-dependent manner whereas no effect was observed in cells expressing hrGFP (Figure 1A). E2FBP1 also down-regulated another PML-NB-associated 560-residue isoform VI of PML (HA-PML-VI) (Figure 1B). Contrary to these results, siRNA-mediated E2FBP1 depletion [21] resulted in an up-regulation of PML (Figure 1C), and the complementation with exogenous E2FBP1 that overcome siRNAmediated down-regulation of E2FBP1 resulted in a distinct down-regulation of exogenous PML-IV (Figure 1D). These results confirmed that E2FBP1 down-regulated the expression of PML regardless of its promoter, and thus possibly at the posttranscriptional level, in dose- 
dependent manner.

To examine whether E2FBP1 mediates polyubiquitylation of PML-IV, 293FT cells were transfected with plasmids expressing HA-PML-IV and E2FBP1. Fortyeight hours of post transfection, cells were further incubated with a proteasome inhibitor MG115 for $8 \mathrm{~h}$ prior to harvest. HA-PML-IV was immunoprecipitated with anti-HA antibody, and the immune complexes were subjected to immunoblotting. As shown in Figure 2A, an increase of slower migrating PML populations $(\geq 100 \mathrm{kDa})$ that was coupled with high molecular weight polyubiquitylated protein species were evident. Moreover, E2FBP1-induced high molecular weight species of HA-PML were modified with Myc-tagged ubiquitin moiety (Figure 2B). These results revealed that E2FBP1 induces polyubiquitylation of HA-PML-IV in vivo.

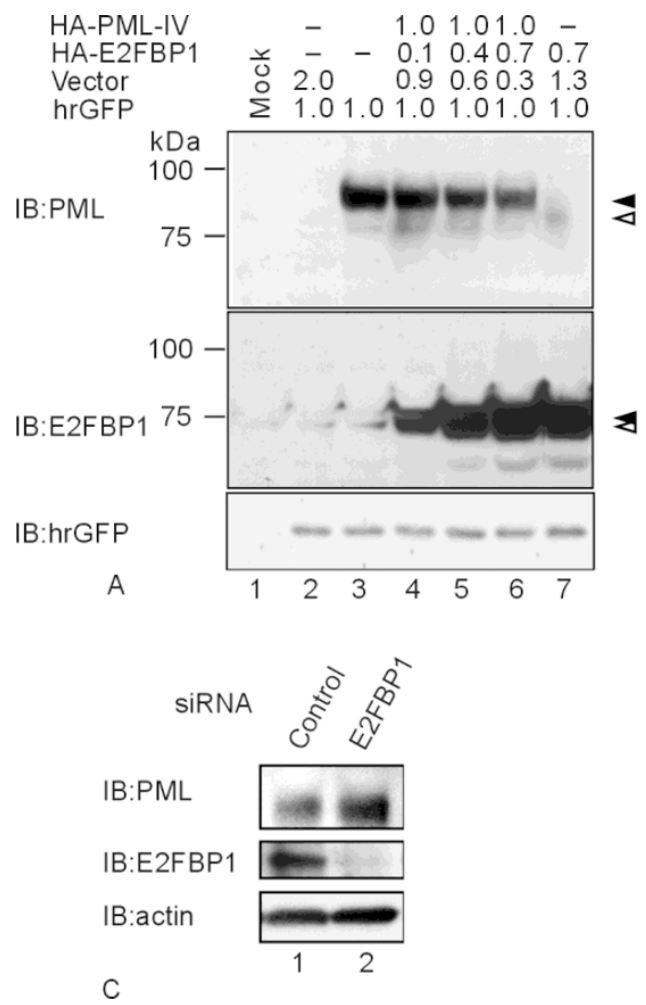

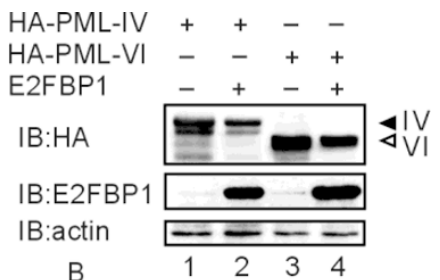

B

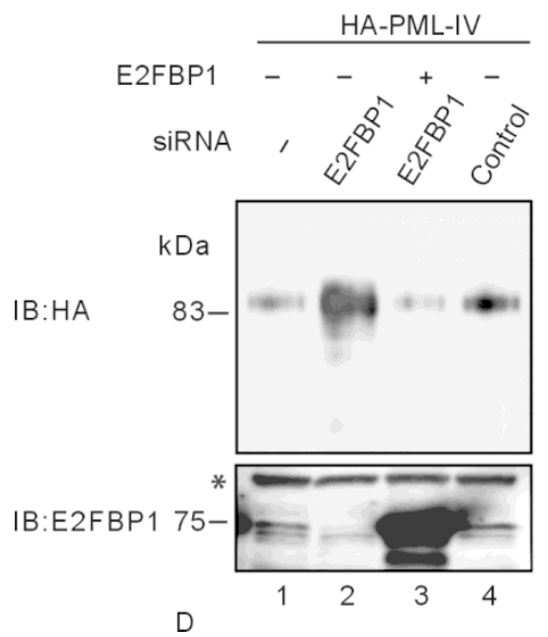

Figure 1 E2FBP1 induces down-regulation of PML. (A) E2FBP1 induces down-regulation of PML-IV in dose dependent manner. 293FT cells $\left(1.7 \times 10^{6}\right)$ plated in $6-\mathrm{cm}$ dishes were transformed with $3 \mu \mathrm{g}$ of expression plasmids mixtures composed of pcDNA3 (vector), pIRES-hrGFP-2, pcDNA-HA-E2FBP1 and pcDNA-HA-PML-IV at indicated ratio. Cell lysates were prepared after two days of cultivation. Thirty-three $\mu \mathrm{g}$ of each lysate was then subjected to immunoblot analyses with antibody for PML (PG-M3), E2FBP1 (BL665) and hrGFP. Open arrowheads and closed arrowheads show endogenous and exogenous antigens, respectively. (B) Both major PML components of PMLNBs are down-regulated under the ectopic expression of E2FBP1. Expression plasmids for either of major PML component of PML-NBs, pcDNA3-HA-PML-IV or pcDNA3-HA-PML-VI was transfected to 293FT cells with or without pcDNA3-HA-E2FBP1, and the cell lysates were similarly subjected to immunoblot analyses. (C) siRNA-mediated down-regulation of endogenous E2FBP1 stabilizes endogenous PML in TIG-3 cells. TIG-3 cells were transformed with siRNA against either E2FBP1 or nonsense control. Two days later, cell lysates were collected, and $15 \mu \mathrm{g}$ of the lysate protein was subjected to immunoblot analysis for PML, E2FBP1 and actin. (D) siRNA-mediated down-regulation of endogenous E2FBP1 stabilizes exogenous HA-PML-IV, and this stabilization is canceled by simultaneous expression of exogenous E2FBP1. 293FT cells were transfected with siRNA against either E2FBP1 or nonsense control. Two days later, the cells were simultaneously transfected with indicated mixtures containing same siRNA and either of following expression plasmid mixtures; HA-PML-IV plus empty vector $(1: 1)$ or HA-PML-IV plus non-tagged E2FBP1 $(1: 1)$, and cultivated for in a further two days. Fifteen $\mu g$ of cell lysate proteins were subjected to immunoblotting for HA and E2FBP1. Asterisk indicates a cross-reactive protein and serves as a loading control. 

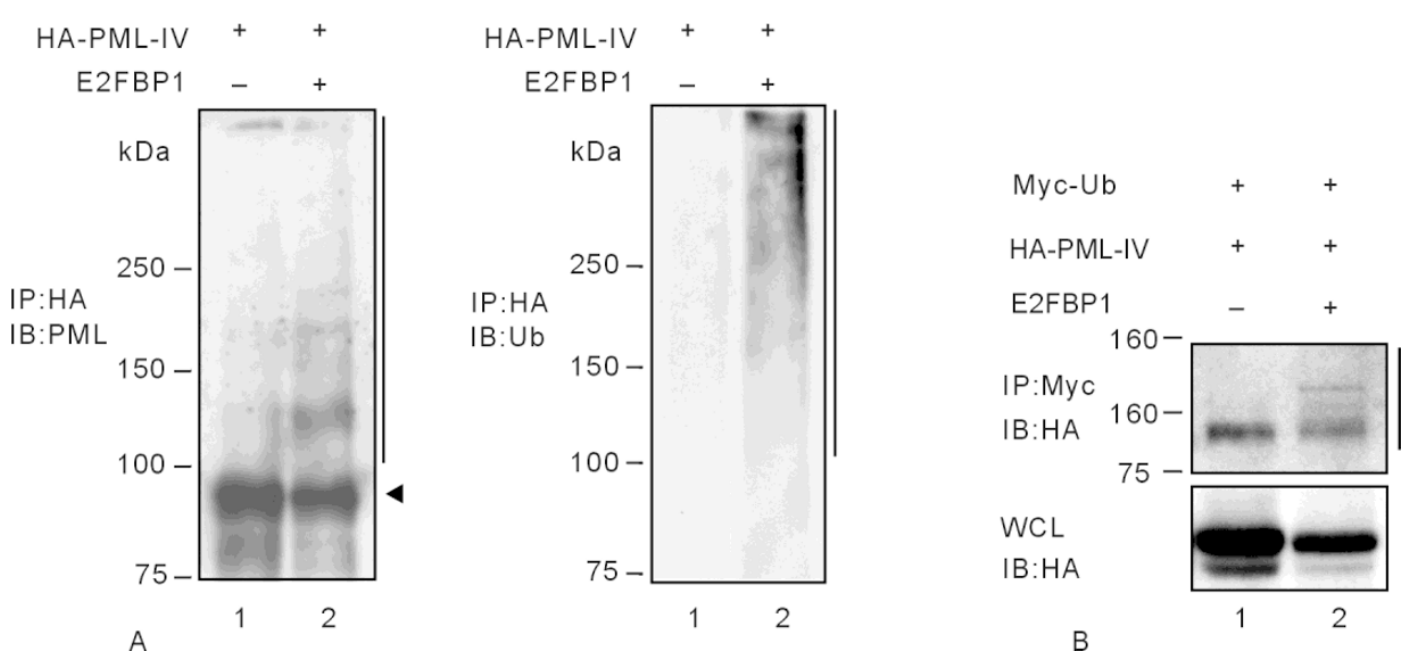

Figure 2 E2FBP1 induces polyubiquitylation of PML. (A) Overexpression of E2FBP1 increases polyubiquitylation of PML-IV in vivo. 293FT cells were transformed with expression plasmids for HA-PML-IV and/or non-tagged E2FBP1 and incubated for two days. The cells were then treated with $10 \mu \mathrm{mol} \cdot \mathrm{L}^{-1} \mathrm{MG} 115$ for an additional $8 \mathrm{~h}$ before cell lysate preparation. HA-PML-IV from $2 \mathrm{mg}$ of lysate was immunoprecipitated with $0.5 \mu \mathrm{g}$ of anti-HA antibody 3F10, and the precipitate was thoroughly washed and subjected to immunoblotting with antibody to PML (PG-M3, upper panel). The blot was then stripped and reprobed with anti-ubiquitin antibody (1B3, lower panel). (B) Overexpression of E2FBP1 increases polyubiquitylation of PML-IV. 293FT cells were transformed with indicated expression plasmids and treated with $10 \mu \mathrm{mol} \cdot \mathrm{L}^{-1}$ of $\mathrm{MG} 115$. After a further $8 \mathrm{~h}$ of cultivation, the cell lysates were subjected to immunoprecipitation with anti-Myc-tag antibody (4A6) followed by immunoblotting with anti-HA antibody (3F10). WCL: whole cell lysate. Bar shows bands of modified HA-PML-IV.

E2FBP1 down-regulation induces premature senescence

Since siRNA-mediated E2FBP1 knockdown induced PML-dependent premature senescence in human primary fibroblast TIG-3 cells, we tested whether down-regulation of E2FBP1 activates Ras-MAPK pathway that results in up-regulation of PML and oncogene-induced premature senescence. TIG-3 cells infected with either lentivirus expressing efficient anti-E2FBP1 short hairpin RNA (shRNA) A2 or A3 exhibited flat enlarged morphology, a characteristic phenotype of senescence and the expression of SA- $\beta$-gal (Figure 3A). SA- $\beta$-gal positive cells were $2.9 \% \pm 0.15 \%, 94 \% \pm 8.5 \%$, and $96 \% \pm 1.8 \%$ for $\mathrm{A} 1, \mathrm{~A} 2$, and $\mathrm{A} 3$, respectively. As expected, the PML expression level was increased in both $\mathrm{A} 2$ and $\mathrm{A} 3$-infected cells, but not A1-infected cells (Figure 3B). The expression levels of Sp100 and Daxx that are major components of PMLNBs were also increased significantly (Figure 3B). Moreover, up-regulation of $\mathrm{p} 16^{\mathrm{INK} 4 \mathrm{~A}}$ and both phosphorylated ERK1/2 (p-ERK1/2) and p38/SAPK (p-p38), and down-regulation of phosphorylated RB were evident in A2 and A3-infected cells but not in A1-infected cells (Figure 3B).

Next we tested the effect of oncogenic Ras ${ }^{\mathrm{V} 12}$, a premature senescence inducer, on the E2FBP1 expression.
$\mathrm{Ras}^{\mathrm{V} 12}$ induced the down-regulation of E2FBP1 along with up-regulations of PML, p16 ${ }^{\mathrm{INK} 4 \mathrm{~A}}$, and hypophosphorylation of $\mathrm{Rb}$ (Figure 3C). These results suggest that the Ras-ERK-p38 signaling axis induces PML-dependent premature senescence at least partly through the downregulation of E2FBP1.

p16 $6^{I N K 4 A}$ plays a critical role in growth suppression initiated by E2FBPI down-regulation

To investigate the role of $16^{\mathrm{INK} 4 \mathrm{~A}}-\mathrm{Rb}$ pathway on the growth arrest induced by down-regulation of E2FBP1, we depleted $\mathrm{p} 16^{\mathrm{INK} 4 \mathrm{~A}}$ simultaneously with E2F2BP1. Depletion of E2FBP1 showed both growth arrest and the characteristic morphology of senescence [21] (Figure 4A, shControl $v s$ shE2FBP1-A2); however, cells transfected with both shp16 $6^{\mathrm{INK} 4 \mathrm{~A}}$ and shE2FBP1 showed recovery in the growth rate and acquired normal morphology after 10 days of lag phase (Figure $4 \mathrm{~A}, \operatorname{shp} 16^{\mathrm{INK} 4 \mathrm{~A}}+$ shE2FBP1-A2). The depletion of both p53 and E2FBP1 increased cell numbers more than four-times greater than that of cells depleted only E2FBP1; however, these double-depleted cells were eventually arrested around Day 15 (Figure 4B). These results suggest that $\mathrm{p} 16^{\mathrm{INK} 4 \mathrm{~A}}$ has a critical role in the growth arrest induced by the 


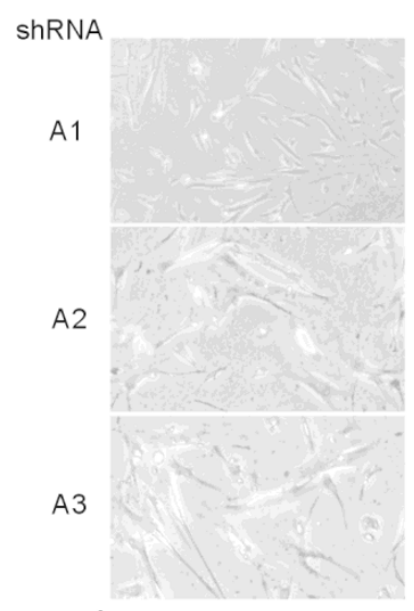

A

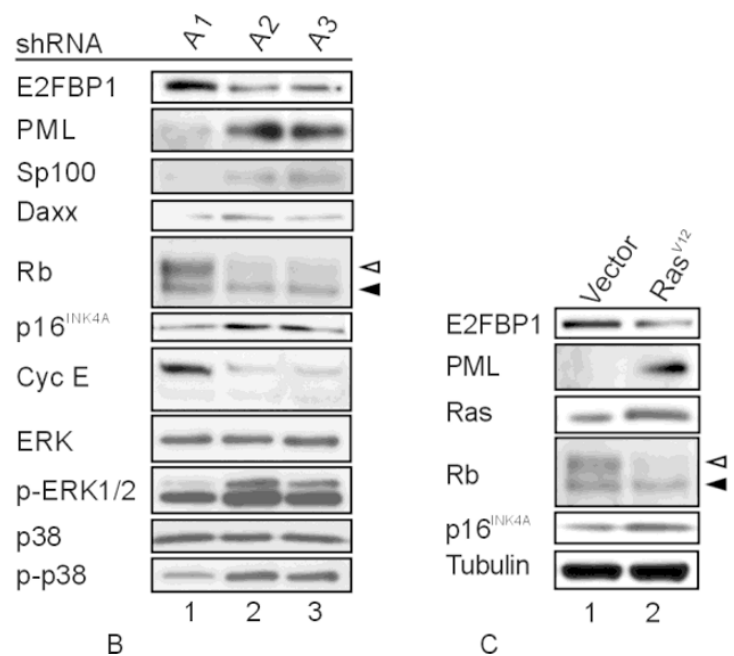

Figure 3 Down-regulation of E2FBP1 accompanies with cellular features of premature senescence. (A) shRNA-mediated down-regulation of E2FBP1 induces premature senescence of TIG-3 cells. Either functional (A2 and $A 3)$ or nonfunctional (A1; serves as a negative control) anti-E2FBP1 shRNA linked to the U6-promoter was introduced to cells by infection with recombinant lentiviruses (multiplicity of infection $(\mathrm{MOI})=2$ ). SA-ß-gal activity was assessed after $14 \mathrm{~d}$ of selection with $4 \mu \mathrm{g} \cdot \mathrm{mL}^{-1}$ brasticidin-S-HCl. (B) Down-regulation of E2FBP1 induced accumulation of PML and up-regulation of phosphorylation of ERK1/2 and p38/SAPK accompanied with premature senescence. TIG-3 cells were infected with the indicated lentiviruses, and selected for $10 \mathrm{~d}$ with $4 \mu \mathrm{g} \cdot \mathrm{mL}^{-1}$ brasticidin-S-hydrochloride. Cell lysates were subjected to immunoblot analyses with indicated antibodies. The open and closed arrows show hyper- and hypo-posphorylated Rb, respectively. Pan-ERK1/2 and pan-p38 serve as loading controls. (C) Ras ${ }^{\mathrm{V} 12}$ down-regulates E2FBP1 expression. Lysates from cells infected with the control (lane 1) or Ras ${ }^{\mathrm{V} 12}$ (lane 2) expressing lentiviruses were subjected to immunoblot analyses with indicated antibodies. The open and closed arrows show hyper- and hypo-phosphorylated Rb, respectively.
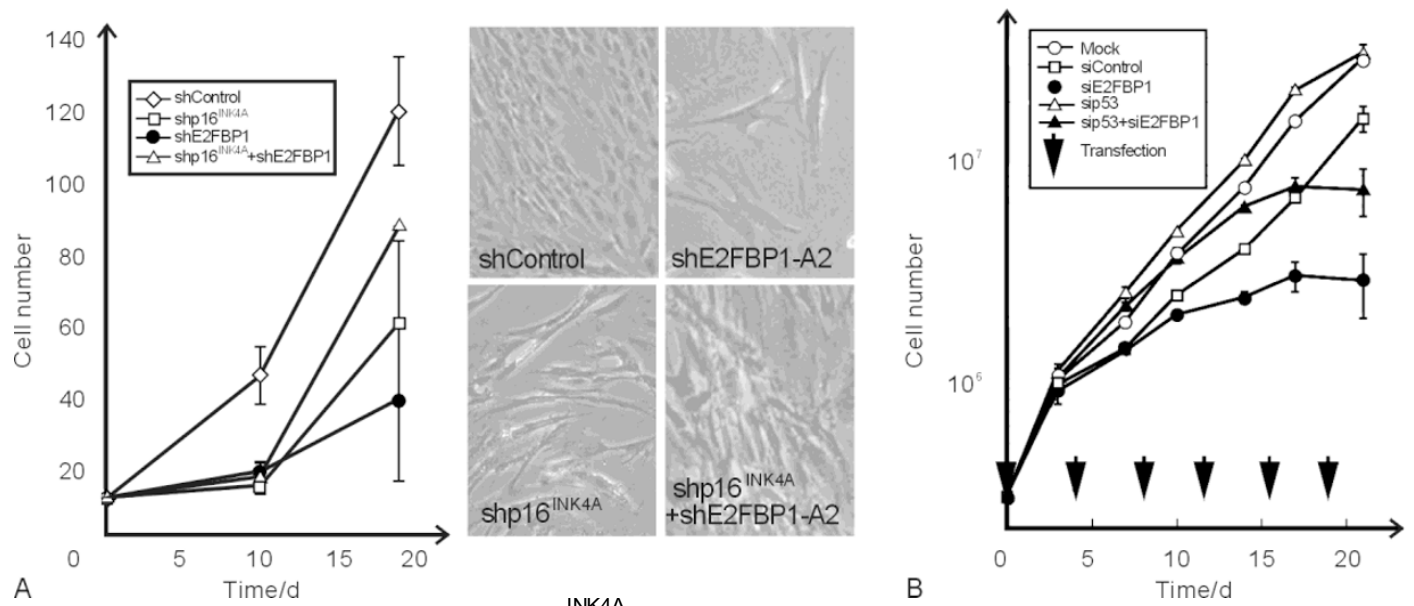

Figure 4 Simultaneous down-regulation of $\mathrm{p} 16^{\mathrm{INK} 4 \mathrm{~A}}$ rescues premature senescence induced by the down-regulation of E2FBP1. (A) The role of $\mathrm{p} 16^{\mathrm{INK} 4 \mathrm{~A}}$ in cell growth suppression induced by down-regulation of E2FBP1 (left). TIG-3 cells were infected with lentiviruses carrying indicated shRNA expression unit, and replated in the presence of brasticidin-S-hydrochloride. Live cell numbers were determined by trypan blue exclusion assay. The values and error bars represent averages and standard deviations of three independent assays. Representative photoimages. Cells infected with lentiviruses expressing indicated shRNA were photographed under phase contrast optics (right). (B) Cell growth suppression induced by down-regulation of E2FBP1 was partly rescued by simultaneous downregulation of p53. TIG-3 cells at 36 PD were treated with indicated siRNAs or mock reagent (M) at every passage (arrow) and counted. The values and error bars represent averages and standard deviations of three independent assays. 
down-regulation of E2FBP1, whereas p53 has only a minor role.

E2FBP1 depletion suppresses tumor cell growth in the presence of intact $p 16^{I N K 4 A}$ and $R b$

To further confirm the roles of $\mathrm{p} 16^{\mathrm{INK} 4 \mathrm{~A}}$ and $\mathrm{p} 53$ in the growth arrest induced by E2FBP1 depletion, we examined seven human tumor cell lines (KB, A431, Hep-2, Saos2, two HCT116 derivatives and MCF7) by colony forming assay. Cells were transfected with either anti-E2FBP1 shRNA or control shRNA expressing plas- mid and selected by puromycin. Colonies were detected by staining with crystal violet (Figure $5 \mathrm{~A}$ and $\mathrm{B}$ ). E2FBP1 depletion clearly reduced the colony formation of $\mathrm{KB}$ and $\mathrm{A} 431$ cells that retain intact $\mathrm{p} 16^{\mathrm{INK} 4 \mathrm{~A}}$ and $\mathrm{Rb}$. In contrast, other cell lines defective in either $\mathrm{p} 16^{\mathrm{INK} 4 \mathrm{~A}}$ and/or $\mathrm{Rb}$ showed no significant effect of E2FBP1depletion on colony formation regardless of p53 status. These observations suggest that $\mathrm{p} 16^{\mathrm{INK} 4 \mathrm{~A}}-\mathrm{Rb}$ pathway plays a critical role on growth arrest of tumor cells induced by E2FBP1 depletion, whereas the p53 status is insignificant.

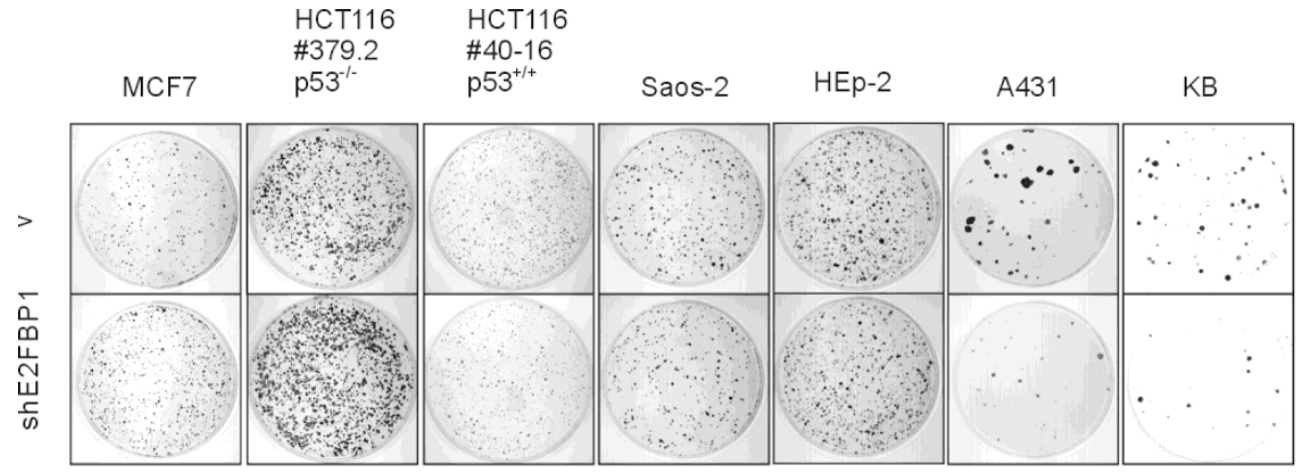

A

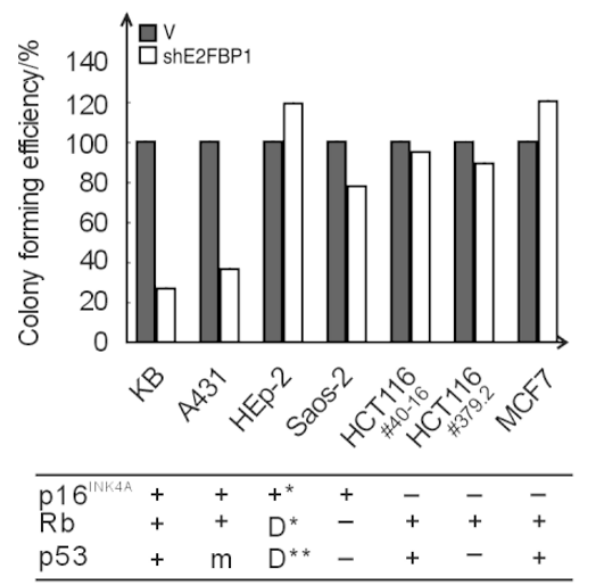

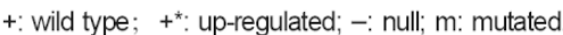
$\mathrm{D}^{*}$ : disturbed by human papiloma cirus (HPV) E7. $D^{* *}$ : disturbed by HPV E6.

$\mathrm{B}$

Figure 5 Down-regulation of E2FBP1 suppresses growth of human cancer cells through the p16 ${ }^{\text {INK4A }}$-Rb pathway. (A) Colony formation of human cancer cells under shRNA-mediated down-regulation of E2FBP1. Indicated human cancer cells were transformed with either piGENE-shControl (V) or piGENE-shE2FBP1 (shE2FBP1). Drug-resistant cells were selected with puromycin for two weeks, and colonies were stained with crystal violet. (B) Colony-forming efficiencies of human tumor cells under shRNA-mediated down-regulation of E2FBP1 is dependent on the status of $\mathrm{p} 16^{\mathrm{INK} 4 \mathrm{~A}} / \mathrm{Rb}$ pathway. The table beneath the chart indicates the status of relevant genes in the respective cell lines. In the chart, vector control was set as $100 \%$ and error bars represent standard deviations of three independent assays. 


\section{Discussion}

Several studies have revealed that functional PMLNBs play significant roles in the induction of both replicative and premature senescence in human fibroblasts and primary mouse embryo fibroblasts [15, 29-33]. Under oncogenic stimulation such as the expression of oncogenic Ras ${ }^{\mathrm{V} 12}$, a transcription factor Ets1 is activated by MAPK, which results in the up-regulation of $\mathrm{p} 16^{\mathrm{INK} 4 \mathrm{~A}}$ for preventing hyperphosphorylation of $\mathrm{Rb}$ and $\mathrm{S}$-phase entry [34]. p16 ${ }^{\mathrm{INK} 4 \mathrm{~A}}-\mathrm{Rb}$ pathway cooperates with mitogenic signals to enforce irreversible cellular senescence through the production of reactive oxygen species (ROS) [35]. In addition, the oncogenic Ras ${ }^{\mathrm{V} 12}$ increases the number of PML-NBs and activates p53 by post-translational modification to induce premature senescence [23]. Our previous report showed that E2FBP1 dissociates PML-NBs through interactions with their components and thus, the down-regulation of E2FBP1 induced the accumulation of PML, Sp100, Daxx and p53 followed by PML-dependent growth arrest in passagelimited HDF cells [21]. Here we describe the molecular mechanism of E2FBP1-dependent dissociation of PMLNBs. E2FBP1 induces ubiquitin-dependent degradation of PML although the mechanism how E2FBP1 induces polyubiquitylation of PML remains elusive. It is possible that E2FBP1 recruits an endogenous ubiquitin ligase that stimulates the degradation of PML.

Since the depletion of E2FBP1 has a significant inhibitory effect on the growth of human cells in the presence of functional $\mathrm{p} 16^{\mathrm{INK} 4 \mathrm{~A}} / \mathrm{Rb}$-pathway regardless of the functional $\mathrm{p} 53$, our results together place E2FBP1 as a crucial regulator for the MAPK-p1 $6^{\mathrm{INK} 4 \mathrm{~A}}-\mathrm{Rb}$ cascade and the formation of PML-NBs during the induction of premature senescence. It has been demonstrated that the accumulated p53 induces premature senescence in cells under certain conditions activated by post-translational modification such as acetylation and phosphorylation [8-9, 23]. Depletion of E2FBP1 accumulates p53; however, we did not see the phosphorylation of Ser 15 in p53 or the induction of $\mathrm{p} 14^{\mathrm{ARF}}$ and $\mathrm{p} 21$ (data not shown). Thus, it is likely that the accumulated p53 is transcriptionally inactive and therefore, $\mathrm{p} 16^{\mathrm{INK} 4 \mathrm{~A}}-\mathrm{Rb}$-dependent senescence plays a major role in the E2FBP1 depletion-dependent induction of premature senescence.

Since our results show that oncogenic Ras ${ }^{\mathrm{V} 12}$ downregulates the amount of E2FBP1, it is assumed that a kinase(s) in the Ras-MAPK pathway affect the stability of E2FBP1 by phosphorylation since E2FBP1 carries several potential phosphorylation target motifs for casein kinase II (CK II ) and cAMP-dependent kinase (PKA) [17]. Studies presented in this manuscript establish an important role of E2FBP 1 in antagonizing $\mathrm{p} 16^{\mathrm{INK} 4 \mathrm{~A}} / \mathrm{Rb}$ - mediated growth suppression and senescence through regulating the protein stability of PML by ubiquitination and PML-NBs dissociation.

\section{Acknowledgments}

We thank Drs. Bert Vogelstein for p53 +/+ and -/HCT116 cell lines, Yoshimi Takai for human H-ras ${ }^{\text {v12 }}$ cDNA, and Ryuji Higashikubo for critical reading of the manuscript. This work was partly supported by a Grant-in Aid for Scientific Research from the Japan Society for the Promotion of Science.

\section{References}

1 Sherr CJ. Cancer cell cycles. Science 1996; 274: 1672-1677.

2 Serrano M, Hannon GJ, Beach D. A new regulatory motif in cell-cycle control causing specific inhibition of cyclin D/CDK4. Nature 1993; 366: 704-707.

3 Sherr CJ, Roberts JM. CDK inhibitors: Positive and negative regulators of G1-phase progression. Genes Dev 1999; 13 1501-1512.

4 Alcorta DA, Xiong Y, Phelps D, et al. Involvement of the cyclin-dependent kinase inhibitor p16 (INK4a) in replicative senescence of normal human fibroblasts. Proc Natl Acad Sci US A 1996; 93: 13742-13747.

5 Hara E, Smith R, Parry D, et al. Regulation of p16CDKN2 expression and its implications for cell immortalization and senescence. Mol Cell Biol 1996; 16: 859-867.

6 Bond J, Jones C, Haughton M, et al. Direct evidence from siRNA-directed "Knock down" that p16 (INK4a) is required for human fibroblast senescence and for limiting Ras-induced epithelial cell proliferation. Exp Cell Res 2004; 292: 151156.

7 Jacobs JJ, de Lange T. Significant role for p16INK4a in p53-independent telomere-directed senescence. Curr Biol 2004; 14: 2302-2308.

8 Prives C, Hall PA. The p53 pathway. J Pathol 1999; 187: 112-126.

9 Appella E, Anderson CW. Post-translational modifications and activation of p53 by genotoxic stresses. Eur J Biochem 2001; 268: 2764-2772.

10 Serrano M, Lin AW, McCurrach ME, Beach D, Lowe SW. Oncogenic Ras provokes premature cell senescence associated with accumulation of p53 and p16INK4a. Cell 1997; 88: 593-602.

11 Zhu J, Woods D, McMahon M, Bishop JM. Senescence of human fibroblasts induced by oncogenic RAF. Genes Dev 1998; 12: 2997-3007.

12 Stein GH, Drullinger LF, Soulard A, Dulic V. Differential roles for cyclin-dependent kinase inhibitors p21 and p16 in the mechanisms of senescence and differentiation in human 
fibroblasts. Mol Cell Biol 1999; 19: 2109-2117.

13 Campisi J, d'Adda di Fagagna F. Cellular senescence: When bad things happen to good cells. Nat Rev Mol Cell Biol 2007; 8: $729-740$.

14 Kuilman T, Michaloglou C, Mooi WJ, Peeper DS. The essence of senescence. Genes Dev 2010; 24: 2463-2479.

15 Sikora E, Arendt T, Bennett M, Narita M. Impact of cellular senescence signature on ageing research. Ageing Res Rev 2011; 10: 146-152.

16 Langley E, Pearson M, Faretta M, et al. Human SIR2 deacetylates $\mathrm{p} 53$ and antagonizes PML/p53-induced cellular senescence. EMBO J 2002; 21: 2383-2396.

17 Suzuki M, Okuyama S, Okamoto S, et al. A novel E2F binding protein with Myc-type HLH motif stimulates E2F-dependent transcription by forming a heterodimer. Oncogene 1998; 17: 853-865.

18 Kortschak RD, Reimann H, Zimmer M, et al. The human dead ringer/bright homolog, DRIL1: cDNA cloning, gene structure, and mapping to D19S886, a marker on 19p13.3 that is strictly linked to the Peutz-Jeghers syndrome. Genomics 1998; 51: 288-292.

19 Kortschak RD, Tucker PW, Saint R. ARID proteins come in from the desert. Trends Biochem Sci 2000; 25: 294-299.

20 Fukuyo Y, Horikoshi N, Ishov AM, Silverstein SJ, Nakajima T. The herpes simplex virus immediate-early ubiquitin ligase ICP0 induces degradation of the ICP0 repressor protein E2FBP1. J Virol 2011; 85: 3356-3366.

21 Fukuyo Y, Mogi K, Tsunematsu Y, Nakajima T. E2FBP1/ HDRIL1 modulates cell growth through downregulation of promyelocytic leukemia bodies. Cell Death Differ 2004; 11: 747-759.

22 Ferbeyre G, de Stanchina E, Querido E, et al. PML is induced by oncogenic ras and promotes premature senescence. Genes Dev 2000; 14: 2015-2027.

23 Pearson M, Carbone R, Sebastiani C, et al. PML regulates p53 acetylation and premature senescence induced by onco- genic Ras. Nature 2000; 406: 207-210.

24 Guo A, Salomoni P, Luo J, et al. The function of PML in p53-dependent apoptosis. Nat Cell Biol 2000; 2: 730-736.

25 Peeper DS, Shvarts A, Brummelkamp T, et al. A functional screen identifies hDRIL1 as an oncogene that rescues RAS-induced senescence. Nat Cell Biol 2002; 4: 148-153.

26 Voorhoeve PM, Agami R. The tumor-suppressive functions of the human INK4a locus. Cancer Cell 2003; 4: 311-319.

27 Maehara K, Yamakoshi K, Ohtani N, et al. Reduction of total E2F/DP activity induces senescence-like cell cycle arrest in cancer cells lacking functional pRB and p53. J Cell Biol 2005; 168: 553-560.

28 Dimri GP, Lee X, Basile G, et al. A biomarker that identifies senescent human cells in culture and in aging skin in vivo. Proc Natl Acad Sci U S A 1995; 92: 9363-9367.

29 Pearson M, Pelicci PG. PML interaction with p53 and its role in apoptosis and replicative senescence. Oncogene 2001; 20: $7250-7256$.

30 Salomoni P, Pandolfi PP. The role of PML in tumor suppression. Cell 2002; 108: 165-170.

31 Takahashi Y, Lallemand-Breitenbach V, Zhu J, de The $\mathrm{H}$. PML nuclear bodies and apoptosis. Oncogene 2004; 23 2819-2824.

32 Zimber A, Nguyen QD, Gespach C. Nuclear bodies and compartments: functional roles and cellular signalling in health and disease. Cell Signal 2004; 16: 1085-1104.

33 Everett RD. Interactions between DNA viruses, ND10 and the DNA damage response. Cell Microbiol 2006; 8 365-374.

34 Ohtani N, Zebedee Z, Huot TJ, et al. Opposing effects of Ets and Id proteins on p16INK4a expression during cellular senescence. Nature 2001; 409: 1067-1070.

35 Takahashi A, Ohtani N, Hara E. Irreversibility of cellular senescence: dual roles of $\mathrm{p} 16 \mathrm{INK} 4 \mathrm{a} / \mathrm{Rb}$-pathway in cell cycle control. Cell Div 2007; 2: 10 . 